\title{
A formação via PNQ e inserção produtiva dos CRAS: a reposição empobrecida e emergencial da qualificação de trabalhadores
}

\section{The background got through the national training plan and the productive insertion in the reference centers for social assistance: the impoverished and emergency replacement of workers'training}

\section{Simone Eliza do Carmo Lessa*}

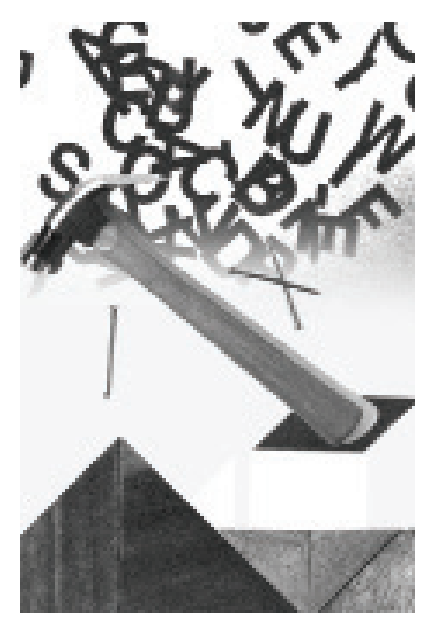

Resumo: Apresentamos aqui reflexões sobre a formação inicial e continuada dos trabalhadores que ocuparão as tarefas menos complexas do mundo do trabalho. Analisamos a execução da qualificação profissional iniciada e continuada de trabalhadores - terminologias contidas na Lei de Diretrizes e Bases da Educação n. 9.494/96 - no Brasil contemporâneo, viabilizada através do Ministério do Trabalho e Emprego, pela via do Plano Nacional de Qualificação (PNQ). Nas margens dessa experiência, apresentamos ainda a aprendizagem que objetiva a geração de renda e a superação da condição de "assistido", denominada de inserção produtiva, executada nos Centros de Referência da Assistência Social (Cras), vinculados ao Ministério do Desenvolvimento Social e do Combate à Fome.

Palavras-chave: Educação. Trabalho. Assistência social. Qualificação de trabalhadores.

Abstract: In this article we discuss the initial and continuing training of workers who will be assigned the less complex tasks in the workplace. We analyze the performance of such initial and continuing training — terminology used in the Executive Education Act 9494/96 — in Brazil nowadays. The Ministry of Labor made such training feasible through the National Training Plan (Plano Nacional de

* Assistente social no Instituto de Aplicação Fernando Rodrigues da Silveira, CAp/Uerj, mestre em Educação (UFF), doutora em Serviço Social (UFRJ) — Rio de Janeiro/RJ, Brasil, professora na Uniabeu, Centro Universitário.E-mail: elizasimone@gmail.com. 
Qualificação - PNQ). We also discuss the training that aims at generating income and overcoming the condition of "assisted". Such training is called productive insertion, and it takes place in the Reference Centers for Social Assistance (Centros de Referência da Assistência Social — CRAS), affiliated to the Ministry of Social Development.

Keywords: Education. Labor. Social services. Workers' training.

\section{0 contexto em que se desenvolve nosso objeto e a falácia da centralidade educacional}

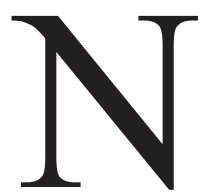

este artigo tratamos da formação de trabalhadores que atuam nos postos de trabalho mais simples e de frágil proteção social. Estamos falando da força de trabalho desempregada e autodenominada autônoma, que busca nos processos de qualificação e requalificação profissional novas possibilidades de acesso, permanência no mercado de trabalho formal ou, ainda, possibilidade de geração de renda, mesmo que na condição de trabalhador informal.

Para compreensão da materialidade do nosso objeto - a qualificação de trabalhadores - , destacamos a força da ideia da formação na sociedade contemporânea, em especial no atual contexto de crise do capital. Nesse marco, frente a uma imensa crise de ordem econômica que apresenta reflexos em todos os campos da vida social, incluindo os processos educativos, recursos materiais — fundos público e privado, aumentados graças à maximização da exploração da força de trabalho - e ideológicos — mídia e formação — são manipulados em prol do enfrentamento desse contexto recessivo.

Buscando entender melhor esse processo, destacamos que o século XXI nasce com uma aparente marca da democratização da informação, da tecnologia e da educação. Os avanços tecnológicos são inegáveis e, ao nível da aparência, a formação e a informação foram democratizadas. De fato, as redes que conectam virtualmente tecnologias diversas e as pessoas por trás das mesmas, fazem parte da vida das camadas médias urbanas e parecem construir relações de novo tipo, criando a falsa noção de que o conhecimento produzido socialmente e dominado historicamente por grupos dotados de grande poder econômico e social — igreja, universidade, burguesia — está agora disponível para todos, superando barreiras de todas as espécies. Ledo engano potencializado ao extremo no plano fenomênico. Tanto a informação - aqui representada pela cha- 
mada "grande mídia" — quanto a formação — processos educacionais de caráter formal - permanecem como objetos de intensa disputa na sociedade, a primeira, claramente controlada pelo grande capital, a segunda, intensamente atravessada por interesses privados e privatistas em relação ao seu fundo público e conteúdos.

Nessa conjuntura de crise capitalista, o conhecimento e mais, do que isso, a educação em seus diversos processos, incluindo aqueles relativos à formação profissional, ressurgem revalorizados, passando a ser denominados de "novo capital" ou "capital social". Trata-se da falácia da sociedade do conhecimento, que tem suas bases na teoria do capital humano, ${ }^{1}$ resgatada por autores como Toffler (1980) e tão bem criticada por Frigotto (1995 e 1998) e Gentili (1994), entre outros.

Este tipo de visão coloca a educação como elemento central (e quase exclusivo) de superação da desigualdade - que aqui denominaremos de centralidade educacional. Destacamos as ideias do empreendedorismo e do produtivismo da formação, da educação por competências e para a vida produtiva, todas limitadoras da formação humana. ${ }^{2}$ Todos esses conceitos foram analisados e criticados por autores como Frigotto (1993 e 1995), Ramos (2001), Rummert (2000) e Fidalgo (2007), por sua fragilidade teórica e submissão a uma visão educativa e de mundo em que o escamoteamento da exploração do trabalho é a tônica.

Segundo a lógica da sociedade do conhecimento é preciso perseguir e conquistar individualmente esse capital, já que ele é o instrumento fundamental

1. Na década de 1950, momento em que os debates sobre o desenvolvimento e o subdesenvolvimento eram intensos, o economista americano Theodore Schultz cunhou o conceito de capital humano (Frigotto, 1998). Segundo este, as diferenças econômicas entre os países do centro e da periferia podem ser explicadas pelas diferenças do nível educacional entre eles. Da mesma forma, trazendo para o âmbito mais individual, as diferenças econômicas e sociais entre os indivíduos poderiam ser creditadas ao investimento que eles fizeram em sua própria educação. Graças a essa teoria, Shultz ganhou o prêmio Nobel de Economia. Isso, porém, somente ocorreu em 1979, no avanço de uma então nova crise do capital, ocasião em que esta teoria teve todos os ingredientes para florescer. Desde então, a teoria do capital humano vem germinando, criando novas folhagens, sem modificar suas raízes.

2. Formação que busca a complexidade e a integralidade do ser humano, oferecendo-lhe instrumentos para a leitura do mundo, intervenção sobre o mesmo, exercício de uma atividade produtiva e domínio dos princípios científicos contidos na mesma (Saviani, 1994). Acrescentamos: formação capaz de permitir que o homem veja e compreenda o mundo para além dele mesmo. 
de ascensão social na contemporaneidade, bem como de superação das diferenças sociais. Portanto, a educação é um tema central e, neste sentido, a busca pela qualificação permanente para a conquista de mais "capital" e de melhor lugar na sociedade é intensamente estimulada e valorizada.

As faces competitiva, individualizante e mercantil do capitalismo, acirradas pela atual crise do capital, transformam a educação e o conhecimento também em objetos mercantilizados. Os resultados do investimento educacional (positivos ou negativos) são também individualizados, chegando à máxima de que o desemprego é resultado da falta de qualificação do trabalhador, mentira que simplifica um tema complexo, a qual, repetida inúmeras vezes, assume ares de verdade no senso comum. Nessa mesma linha de idealização e maximização das potencialidades da política educacional, encontramos o pensamento denominado educacionismo, ${ }^{3}$ que credita exclusivamente a essa política as possibilidades de construção de justiça social.

Como expressão cotidiana desse processo, destacamos as recomendações empresariais em torno da permanente qualificação da força de trabalho, na intenção de torná-la competitiva frente à dinâmica econômica internacional, como as propaladas pela CNI (2007). Nessa ótica, a formação é transformada em instrumento para prover produtividade e fica resumida ao viés economicista, fragilizando suas possibilidades de crítica da realidade.

Destacando que o referido produtivismo reduz a formação à execução de uma dada tarefa no mundo do trabalho e cientes de que este processo não é novo, visto que recomendações do capital no sentido da associação entre qualificação e produtividade datam do início da industrialização do Brasil (Rodrigues, 1998), queremos argumentar que existe uma "novidade" nesse processo. Tal "novidade" diz respeito à maximização da potencialidade da educação frente aos processos produtivos. Detalhemos a reflexão. O Brasil é um país que realizou sua industrialização sem o suporte da escola (Cunha, 1995). Os trabalhadores dos campos mais simples em termos ocupacionais ficavam relegados ao aprendizado de suas tarefas nos próprios ambientes de trabalho e aprendiam fazendo, sem suporte educacional formal. Essa conduta vem mudando, e as

3. O professor Christóvão Buarque, da UnB, argumenta que o educacionismo é uma perspectiva teórica que coloca as ações do campo educacional como atividade central de transformação do mundo contemporâneo. Para esse autor, entre outros que lhe são afiliados, a constituição de uma rede escolar pública para todos seria instrumento capaz de transformar e superar as desigualdades sociais do país. 
prescrições quanto à qualificação permanente e a valorização do capital-conhecimento têm chegado aos trabalhadores das áreas mais simples, historicamente relegados ao aprendizado na realização da tarefa produtiva em si.

Estamos falando de cursos de curtíssima duração, voltados especialmente para ocupações no setor de serviços, - atividades administrativas simples, informática básica, cozinha, reparos domésticos (campos de destaque na aprendizagem profissional, segundo a PNAD (2007), divulgada amplamente nos meios de comunicação). ${ }^{4}$ Falamos também de cursos que objetivam preparar (e naturalizar) o trabalho informal, oferecendo fundamentos para o trabalhador "empreender", ou seja, para organizar um pequeno negócio, em geral relacionado ao comércio ambulante. Estes cursos são oferecidos por instituições privadas como ONGs e o Sistema "S", em sua maioria, mas no primeiro grupo citado, também por instituições públicas, como as escolas técnicas estaduais.

Nosso argumento é de que, diferentemente do passado, quando aprender no ambiente produtivo era o suficiente para o trabalhador dos campos mais simples, as prescrições para a qualificação permanente estão chegando à mão de obra das ocupações mais básicas, aqueles que realizam as tarefas menos complexas, repetitivas, insalubres, menos protegidas legalmente e destituídas de status, visto que detêm característica bastante manual. Buscando compreender esse processo, discutimos a qualificação de trabalhadores realizada por meio do Plano Nacional de Qualificação (PNQ), vinculado ao Sistema Público de Emprego (SPE) e estruturado pelo Ministério do Trabalho e Emprego (MTE) no governo Lula da Silva.

Nas margens dessa experiência, em situação ainda mais frágil, analisamos ainda outro modelo de aprendizagem para o trabalho, denominado de inserção produtiva, viabilizado através dos Cras (Centros de Referência da Assistência Social), estruturados a partir do Suas (Sistema Único da Assistência Social), vinculados ao Ministério do Desenvolvimento Social e Combate à Fome (MDS). Atentemos para o fato de que, apesar de tratarmos de uma política de formação, não fizemos nenhuma menção ao MEC (Ministério da Educação), o que denota que a aprendizagem de trabalhadores tal como está estruturada orbita marginalmente a educação oficial.

4. Aqui citamos material divulgado pelo Observatório Jovem/UFF e em jornais como O Globo, Jornal do Brasil e Folha de S.Paulo. 
A opção por esse objeto nasce de sua relevância social, da nossa experiência profissional com jovens trabalhadores em busca de qualificação, bem como da certeza de que, analisando o PNQ e a inserção produtiva dos Cras, podemos conhecer elementos importantes da formação de trabalhadores das periferias econômicas, sua concretização e sofisticação — ainda que esta não rompa com a precariedade da experiência. Também entendemos que nessas estruturas estão contidos os contornos e as tensões da relação entre o capital e trabalho e entre projetos de formação partidos pela dualidade estrutural ${ }^{5}$ — para os trabalhadores, formação focada na produção, destituída de base científica e atitudinal, e para a burguesia, formação ampla, complexa e fundamentada na ciência. Por fim, entendemos ainda que ao estudarmos criticamente a qualificação de trabalhadores hoje, poderemos contribuir com os questionamentos em torno da sociedade do conhecimento e da centralidade (exclusiva) da política educacional.

Para realizarmos essa argumentação, analisamos as qualificações profissionais iniciais de trabalhadores, por meio dos dados do PNQ, disponibilizados nos Anuários de Qualificação Social e Profissional do Departamento Intersindical de Estatística e Estudos Socioeconômicos (Dieese) e do Ministério do Trabalho e Renda (2006, 2007, 2008), dos documentos de avaliação do Plano produzidos pela Unitrabalho. ${ }^{6}$ De modo especial, analisamos os dados coletados nas Secretarias de Trabalho e Renda, tanto do estado quanto do município do Rio de Janeiro, referentes ao período 2005-08. Também levantamos e analisamos o perfil das aprendizagens viabilizadas na modalidade de inserção produtiva realizada nos Cras, oferecida em nove municípios $^{7}$ localizados na região me-

5. A sociedade capitalista é marcada pela cisão entre os detentores dos meios de produção e aqueles que detêm somente sua a força de trabalho. Este quadro de desigualdade se expressa em condições desiguais de existência, e as políticas educacionais são um dos espaços de sua evidência. Como concretização dessa dualidade citamos a formação a que tem acesso a elite e aquela a que têm acesso os trabalhadores. Em uma sociedade complexa como a capitalista contemporânea, essa dualidade é escalonada, formando segmentos de trabalhadores de aprendizados distintos: quanto mais periférico seu lugar na produção, mais simplificada e periférica a sua formação.

6. No Brasil, a Rede Unitrabalho é composta por 92 universidades e instituições de ensino superior, que desenvolvem projetos, pesquisas e capacitações sobre o trabalho. Esta rede é responsável pela avaliação do Plano Nacional de Qualificação. Nossa análise foi elaborada, principalmente, sobre os documentos "Políticas públicas de qualificação: desafios atuais" e o "Novo momento para as comissões de emprego no Brasil?", citados em nossa bibliografia.

7. Decidimos por não identificar nominalmente os municípios analisados, uma vez que isso poderia revelar quem foram os profissionais que nos receberam. Ressaltamos que as equipes que executam a política 
tropolitana do Rio de Janeiro, notadamente na Baixada Fluminense. ${ }^{8}$ A esse material de análise somam-se dados de instituições como o Instituto Brasileiro de Geografia e Estatística (IBGE), o Instituto de Pesquisa Econômica Aplicada (Ipea) e o Ministério da Educação (MEC), como fontes de consulta.

Ademais, utilizamos levantamento próprio, realizado durante oito meses, sobre as notícias diárias quanto à aprendizagem profissional, no Brasil, com foco especial na região Sudeste e, mais especificamente, no estado do Rio de Janeiro. Tais informações foram divulgadas nos principais veículos de comunicação, via internet, e chegaram diariamente até nós, por meio de ferramenta de informática de busca de conteúdos a partir de palavras-chave. Com base neste levantamento, tivemos acesso às principais notícias/informes dos ministérios, divulgação de cursos e reportagens contemporâneas sobre a qualificação inicial de trabalhadores via PNQ, bem como sobre as aprendizagens realizadas nos Cras. Por intermédio deles, pudemos encontrar elementos para analisar características da educação profissional inicial de trabalhadores, suas formas de divulgação e características. Tais informações foram fundamentais para melhor compreensão do nosso objeto, seus objetivos declarados e sua concretização.

\section{Capitalismo e formação de trabalhadores: uma aproximação interessada}

Mais uma vez o capitalismo passa por uma de suas crises cíclicas. A atual demonstra ser de longa duração, visto que sua origem data do início da década de 1970 e de graves feições. Seu enfrentamento parece ineficaz, a julgar por

\footnotetext{
de assistência social hoje (na Baixada e nacionalmente), em sua ampla maioria, possuem vínculos instáveis de trabalho e muita precariedade em seu cotidiano profissional. Apesar da disponibilidade em falar da sua realidade, o temor pelas consequências desse ato era uma constante - o que nos parecia bastante real, especialmente no período de transição eleitoral no qual a maior parte da pesquisa foi realizada. Destacamos, ainda, que essa amostragem foi baseada na disponibilidade dos profissionais e gestores, mas é bastante representativa, visto que chegamos aos dados de nove cidades, em um território composto por catorze municípios, o que nos dá uma marca de $64 \%$ do total.

8. Também pesquisamos dados referentes aos Cras, do município do Rio de Janeiro (RJ), mas estes foram descartados em nossa análise, pelo tratamento específico da experiência da capital. Melhor explicitando, no Rio de Janeiro, a inserção produtiva na gestão César Maia é uma ação articulada à Escola Carioca de Empreendedorismo, e não está voltada para todos os usuários dos Cras, mas somente para aqueles que apresentem perfil "empreendedor", o que nos pareceu um critério bastante subjetivo e inadequado frente à política de assistência social. Por esta particularidade, descartamos esses dados.
} 
acontecimentos recentes nos países do capitalismo central. ${ }^{9}$ Seu aprofundamento guarda relação com o descompasso entre os processos de acumulação e os de consumo como aspecto mais geral e tem como causa mais imediata, conforme Gonçalves (2008), a amplíssima insolvência iniciada no sistema de hipotecas imobiliárias americanas. Os reflexos da crise são visíveis: governos estão mobilizados para reunir recursos públicos ou, segundo o jargão econômico, oferecer liquidez ao capital, na intenção de salvaguardá-lo. Como esse objetivo, instituições financeiras privadas têm tido seus prejuízos estatizados, tanto no capitalismo central como no periférico. Tal situação não deve ser considerada inédita, uma vez que a transferência de recursos públicos para o campo privado é um elemento de sustentação do padrão capitalista de acumulação. A crise atual deve ser analisada especialmente por sua extensão mundial, pela rapidez com que providências no sentido de seu enfrentamento foram tomadas e pela junção de pensamentos diversos na justificativa da ação estatal para aplacá-la — da ultra direita à pseudoesquerda, todos ponderam a respeito da positividade do Estado no suporte ao capital.

Os reflexos dessa crise no mundo do trabalho têm aprofundado aspectos inerentes ao capitalismo, como a desigualdade e a desproteção de significativas faixas de trabalhadores. Neste sentido, crescem o desemprego e a proteção ao capital e decrescem os níveis de renda dos trabalhadores e a estrutura da seguridade, mas nesse campo as respostas do poder público não são tão rápidas. Certamente, é da redução dos custos relativos aos salários e da proteção social, além da maximização da exploração, que sairá a base financeira de proteção do capital.

Esse contexto tem reflexos que vão além da materialidade do mundo da produção, repercutindo no campo das ideias: a crise precisa ser entendida como um elemento natural da ordem econômica, plenamente superável se todos (leia-se, os trabalhadores) cooperarem. Aos mesmos são solicitadas posturas de benevolência para com o capital, como a redução de salários, a ampliação de jornadas de trabalho sem a correspondente remuneração, o abandono de direitos conquistados; tudo isso, segundo o capital, para salvaguardar postos de trabalho.

9. Falamos da crise de grandes proporções por que passam países europeus, como Grécia, Espanha e França. 
Analisando o nosso objeto no referido contexto, entendemos que diante da crise atual está havendo o crescimento da valorização da qualificação permanente para a vida produtiva e da falácia de que o desemprego é resultado da falta de formação e de empenho individual, o que tem repercutido nas políticas educacionais e de formação de trabalhadores. Avaliamos, portanto, que no atual contexto as ideologias da sociedade do conhecimento e da centralidade educacional serão ainda mais valorizadas, enquanto os processos de formação humana, em sentido amplo, serão duramente atingidos.

Olhemos para a formação de trabalhadores. Primeiramente vale lembrar que o capital, ao longo de sua história, organiza-se no sentido de assegurar sua reprodução, rebaixando os custos com a força de trabalho - esta que é a mais eficaz estratégia para fazer crescer a acumulação de capital (Marx, 1985). Por esta razão, na relação capital/trabalho a negação, a restrição e/ou a conquista de direitos compõem uma página em permanente construção e tensão, gerando avanços e retrocessos na história do capitalismo. Na fase atual, o resultado dessa tensão atende pelo nome de neoliberalismo, que se faz presente na gestão da economia, com reflexos dessa na vida social. As práticas neoliberais potencializam os ataques aos direitos dos trabalhadore ${ }^{10}$ com o aval do Estado (Soares, 2002), sendo traduzidas no campo das ideias pelas interpretações pós-modernas (Harvey, 2003).

Nesse sentido, novas políticas gerenciais são instituídas na intenção de elevar patamares de produtividade e fazer crescer a extração de mais-valia. Estamos falando da importação de orientações para a organização da produção e para a gestão da mão de obra, em especial dos americanos e japoneses — tais como as células, a produção horizontalizada, o sistema "just in time", os "programas de qualidade de vida", os círculos de produção — que surgem aliados às terceirizações e à precarização do trabalho ${ }^{11}$. A intenção é conquistar a adesão dos trabalhadores a estas ações que prometem tornar os ambientes ocupa-

10. Analisando documento do Banco Mundial, Borón (2003) destaca a orientação deste organismo de financiamento para a América Latina na década de 1990: abandonar o chamado intervencionismo estatal pelo supostamente mais eficiente modelo de liberalização centrado no mercado.

11. Lembramos de Martins (2001) que em seu estudo aponta que os processos de reestruturação produtiva atingiram muito mais a organização da mão de obra do que o aparato produtivo propriamente dito. Nosso modelo reestruturador periférico atinge aos trabalhadores, barateando ainda mais os custos da produção, mas não chega a transformar significativamente o parque industrial, pelos custos que essa prática teria. 
cionais mais eficientes, produtivos, menos áridos e, por que não dizer, mais "afetivos".

A apresentação destas formas de organização do trabalho é feita sob viés pseudocientífico. Estas afirmam-se supostamente "neutras", com intenções de meramente tornar os espaços de trabalho lugares de melhor convivência. Não por acaso, essas iniciativas se multiplicam nesse contexto recessivo. Gurgel (2003) sinaliza o caráter ideológico dessas propostas desvendando que sua intenção, além do aumento da produtividade, é a captura da subjetividade do trabalhador a favor do capital e o escamoteamento da luta de classes. O caráter predatório do capital sobre a força de trabalho fica evidente, apesar de sinalizada "neutralidade".

As relações de trabalho, por sua vez, estão diretamente submetidas à constituição deste modelo produtivo. Desta forma, os paradigmas de gestão de mão de obra acima identificados tentarão moldar o trabalhador ideal para o atual padrão produtivo - disponível, produtivo, dotado de multi-habilitações, capaz de se autogerenciar e de tomar conta dos colegas, agressivo na competitividade e na produtividade, mas disponível e dócil para a exploração. Pela complexidade da tarefa, porém, outras instituições sociais, muito além do ambiente de trabalho, serão convocadas para agir. Trata-se de tarefa formativa importante, de grande apelo ideológico, que precisa ser massificada para ter êxito. Estamos falando da escola, das instituições de formação de trabalhadores e da mídia, embora possamos vislumbrar até mesmo as religiões na concretização desse processo. Através delas, o perfil de trabalhador produtivo e dócil precisa ser estimulado. Certamente, existem resistências dos trabalhadores a esse processo, mas a força do mesmo na atual conjuntura é inegável.

Para além das prescrições organizacionais e das instituições de formação, estamos vivendo momento de ampliação do trabalho temporário, terceirizado e precário. Desprotegida, essa mão de obra sobrevive alternando informalidade e formalidade, com remunerações instáveis em atividades simples, que não exigem, de modo geral, qualificação prévia específica para aquela tarefa (Pochmman, 1998). Diante da evidente diminuição do proletariado fabril, na outra face dessa mesma moeda, cresceram o trabalho precário e a subproletarização (Antunes, 1995). A modernização dos campos centrais da produção se constrói a partir da precarização de outros (Alves, 2000), organizando experiências de trabalho distintas, com maior e menor índice de proteção social. 
Estudo do Ipea realizado por Campos e Amorim (2007) revela que, neste marco, o setor de serviços tem crescido significativamente. Trata-se, de fato, de um campo de trabalho em expansão que tem superado quantitativamente a indústria, inclusive a de transformação e extrativismo, tradicionalmente dotadas de grande potência e de absorção significativa de mão de obra.

Observando nosso objeto de análise, não por acaso, a área de serviços é a que mais oferece qualificações no PNQ. Nesse mesmo sentido, não é coincidência que a inserção produtiva dos Cras seja organizada sobre aprendizados que remeterão ao comércio informal e às habilidades domésticas. Por essa razão, os trabalhadores atuantes nos setores periféricos e aqueles que vivenciam a subproletarização, apesar de parecerem estar fora desse processo que valoriza a produtividade e o adestramento de mão de obra formal, não podem estar à parte das orientações gerenciais para a força de trabalho central. Muito pelo contrário. Eles não estão livres dos ajustes feitos para os trabalhadores mais centrais da produção, tampouco das prescrições dos modelos gerenciais aqui citados. A crise atual demanda que esse trabalhador seja (re)educado. Desta forma, apesar da frágil qualificação técnica, específica para o exercício de um ofício, há muito o que formar em relação à produtividade e à naturalização das péssimas condições de trabalho

Vale frisar, porém, que as formas como essas determinações chegam até os trabalhadores dos campos mais centrais e aqueles que atuam nas periferias é que são distintas. Se a tendência à desproteção e à intensificação da precarização atinge a mão de obra mais protegida e central nos processos produtivos, para os que estão nas periferias não é diferente. Se para os primeiros a ameaça está relacionada às demissões, terceirizações, maximização da exploração e da produtividade, exigência permanente de requalificação profissional, para os demais, dentro dessa mesma lógica, as ameaças estão na ampliação das dificuldades de acesso à formalidade, nas exigências em torno da empregabilidade, na execução de tarefas cada vez mais precárias e simplificadas, na aceitação de condições desprotegidas de trabalho, no estímulo às requalificações frágeis e permanentes. Vejamos que para ambas as condições — proletários e subproletários - a exigência da aprendizagem para o trabalho e a adequação de conduta aos códigos da produção se evidenciam, gerando, portanto, uma formação interessada (Gramsci, 1988), estreita, simples em conteúdos, mas sofisticada e complexa em termos de demandas sociais e econômicas do capital, ali embutidos especialmente a produtividade e o apassivamento. Tais exigências, porém, 
não se concretizam no acesso ao emprego, em especial para o segundo grupo citado, ficando apenas no campo da promessa integradora (Gentili, 1994).

Depois de relacionarmos o modelo de produção à gerência das forças produtivas e sua tentativa de adequação do trabalhador às mesmas, é hora de uma análise mais detalhada do campo da formação. O capitalismo necessita e o neoliberalismo busca prover um tipo de formação submetida ao mercado e à flexibilidade, detentora de conhecimentos interessados (Gramsci, 1988), apartada da compreensão do mundo e limitada às necessidades de prover agilidade à produção que é revolucionada permanentemente.

Dando suporte ideológico a esse processo, destacamos a valorização do papel do mercado nas relações sociais. Alçado ao status de poder central e provedor de justiça, o mercado supostamente identifica indivíduos mais aptos ao trabalho, os que mais se empenharam em prol de sua própria educação. Neste sentido, os processos educacionais ficam limitados ao papel de dar suporte para acesso ao mercado, o que desqualifica sua dimensão crítica. Feita esta breve reflexão sobre a formação contemporânea como pano de fundo para compreensão do nosso objeto de estudo, passaremos a analisar as experiências do PNQ e da inserção produtiva.

\section{O PNQ e a inserção produtiva no governo Lula da Silva: a sofisticação da aprendizagem simples}

O Plano Nacional de Qualificação (PNQ), integrado ao Sistema Público de Emprego, ${ }^{12}$ é a segunda experiência de organização de política de formação de trabalhadores ${ }^{13}$ de caráter nacional. A primeira delas foi o Plano Nacional de Qualificação do Trabalhador (Planfor) organizado e desenvolvido nos dois governos FHC, como concretização das políticas neoliberais, por suas

12. O Sistema Público de Emprego, Trabalho e Renda é uma estrutura do Ministério do Trabalho que agrega ações diversas: seguro-desemprego, recolocação no mercado de trabalho, qualificação profissional e combate ao trabalho escravo são algumas destas. Sua estruturação no Brasil é bastante recente (data da ditadura).

13. A primeira experiência de um plano especificamente montado para essa finalidade foi o Plano Nacional de Qualificação do Trabalhador (Planfor), implementado nos dois governos FHC, no período de 1995 a 2002. Essa experiência foi efetivada por meio de formações aligeiradas, frágeis em conteúdos científicos e voltadas para as necessidades do mercado. Sobre o tema, ver a excelente reflexão de Cea (2006). 
prescrições ao empreendedorismo e para a qualificação submetida ao mercado (Cea, 2006).

O PNQ está estruturado por meio de ações territoriais (no caso do PlanTeQ) e por demandas setoriais (PlanSeQ), estando voltado diretamente para a força de trabalho em exercício ou em busca de emprego, ou seja, para a PEA. Apesar desse aparente foco genérico, o Plano está, de fato, voltado para trabalhadores que desenvolverão as atividades mais simples, o que pode ser comprovado pelas áreas dos aprendizados oferecidos, assim como pelo perfil dos usuários que chegam aos cursos, como se pode verificar nos Anuários de Trabalhadores de 2005 a 2008.

Esses são trabalhadores desempregados ou autônomos, encaminhados pelo Sine para a qualificação e suposta reintegração ao mercado de trabalho. São também (a partir de junho de 2008), usuários do Bolsa Família — por meio do PlanSeQ/BF, agora denominado de Programa Próximo Passo - convocados para integrar formações do campo da construção civil (especialmente). Vale frisar que a divulgação das referidas qualificações é realizada principalmente nas agências do Sine e por intermédio do MDS (no segundo caso), o que minimiza as possibilidades de que um trabalhador desempregado há mais tempo, ou com uma história de vida ocupacional na informalidade, chegue autonomamente a essa política.

Analisando o documento que institui o PNQ (Brasil, MTE, 2003-07), encontramos um material gerado em condições históricas de novo tipo, e é essa a primeira consideração sobre o Plano que pretendemos fazer. "Nunca na história deste país" é uma das célebres frases de Lula da Silva que traduzirá muito bem o que pretendemos dizer. Nunca na história deste país foi tão complexo analisar as ações governamentais. Isto porque a combinação, em condição de proposição e de mando, de atores políticos com trajetórias de ação distintas - grupos oriundos do PT, partido que apesar de ter passado por processo de transformação de sua visão de sociedade e de poder ao longo de sua existência, possuía ainda propostas progressistas no campo das políticas sociais, combinados aos grupos mais conservadores, que se perpetuam nos espaços públicos ao longo de décadas - , tem gerado como fruto ações governamentais dotadas de continuísmo, sob o argumento da inovação.

Trata-se de uma renovação do discurso - no caso do PNQ, encontramos alusão à educação integral em seu documento instituinte, por exemplo — e uma 
reposição concreta das práticas conservadoras - uma vez que apesar do discurso, a infraestrutura para efetivação de uma formação de trabalhadores com qualidade é inexistente.

Sendo assim, o resultado dessa união é a junção de um quebra-cabeças em que as peças não se encaixam, apesar de estarem formando a mesma imagem. Este fato traduz a complexidade da sociedade brasileira contemporânea e expressa a incorporação de interesses diversos - articulados nos limites da subordinação aos interesses do capital — no interior de um padrão de Estado possuidor de perfil inusitado e contraditório: democrático, mas patrimonialista e clientelista, possuidor de base legal que garante alguns mecanismos de controle social (como os Conselhos de Participação e de Direitos), mas centralizador e com dificuldades de incorporar demandas públicas por justiça social. Neste sentido, é oportuna a reflexão de Barata (2009), quando afirma que o governo Lula da Silva começa a se afastar de suas bandeiras históricas quanto mais se aproxima do poder e das disputas eleitorais.

Feitas essas considerações iniciais, passemos a apresentar alguns breves dados sobre a efetivação do Plano. Iniciemos por sua abrangência. O PNQ pretende atingir uma meta mínima de $20 \%$ da PEA ao final de sua execução. No entanto, apesar de seu caráter nacional e de significativa divulgação em torno de seu amplo papel, tem atingido uma média anual de 100 mil trabalhadores brasileiros, em âmbito nacional, e este número está em queda. Lembremos que a taxa nacional de desocupação da força de trabalho é da ordem de $10 \%$, o que se comparado aos usuários atendidos no Plano, revelará seu caráter pontual e fragilíssimo frente às demandas por formação. Podemos afirmar, portanto, que a abrangência dessa ação tem sido pequena e insuficiente para um programa de perfil nacional. Em outras palavras, o PNQ está muito aquém do divulgado pelo governo.

Sobre o público-alvo, dentre os grupos arrolados como prioritários, por serem compreendidos como dotados de grande vulnerabilidade social, ${ }^{14}$ encontramos as minorias étnicas — em especial negros e indígenas - , as mulheres,

14. Esta terminologia tem sido muito utilizada no campo das políticas sociais em tempos neoliberais, especialmente por organismos internacionais de financiamento. Os mais vulneráveis são analisados segundo territórios e necessidades. O termo traduz a meta da focalização de uma ação em determinado público que apresenta maior demanda socioeconômica. Esse tipo de conduta está associado à exigência de condicionalidades e tende a caminhar no sentido inverso na universalização de direitos. 
os jovens e indivíduos de baixa escolaridade, subempregados e desempregados. Vejamos como essas metas têm sido cumpridas. De fato, as mulheres representam o grupo mais atendido em termos quantitativos pelo PNQ, pois além de o perfil dos cursos indicarem uma "feminização" das aprendizagens, o gênero feminino tem sido público prioritário de muitas políticas contemporâneas de recorte social. A justificativa dos planejadores para tanto, diz respeito à capacidade feminina de multiplicar a informação, bem como por seu papel central nas famílias. Vale ressaltar que essa valorização é estimulada por organismos de financiamento com os quais os governos dialogam e estabelecem parcerias, tais como o Banco Mundial.

Já sobre a questão étnica, ressaltamos que os autodeclarados negros e pardos representam uma média de 50\% dos usuários do Plano, em nível nacional, denotando que não há uma absorção especial ou prioritária desse público em relação aos demais. Dentre os egressos, encontramos uma média de 38\% de negros e pardos, o que está em consonância com os níveis de desistência dos cursos também para os brancos.

Quanto aos jovens verificamos que uma média de $37 \%$ do total de usuários está na faixa entre 16-24 anos, nacionalmente, e que no Rio de Janeiro este número é de $35 \%$, o que demonstra que essa política não pode ser denominada como ação específica para essa condição etária. No entanto, vale resgatar que os recursos do Projovem Trabalhador ${ }^{15}$ — programa que prevê a qualificação de jovens de 18 a 29 anos, desempregados e que venham de famílias cuja renda per capita seja de até um salário mínimo - têm crescido. Este fundo é oriundo do PNQ, mas o Projovem ocupa uma estrutura específica.

Lembramos que os números apresentados acima dizem respeito aos jovens atendidos exclusivamente no PNQ, objeto ora analisado por nós e que os atendimentos do Projovem são maiores do que os do Plano, ainda que a qualidade da formação viabilizada seja também objeto de questionamento. ${ }^{16}$ Ainda assim,

15. Projovem é o resultado da unificação do Consórcio da Juventude, Escola de Fábrica e Juventude Cidadã, anteriormente praticados pelo governo Lula da Silva, que tiveram suas metas de atendimento bem abaixo do previsto. A partir de 2009 o programa foi redividido nas modalidades Projovem Adolescente, Campo, Urbano e Trabalhador. O Projovem é gerenciado pela Secretaria Nacional de Juventude, pelo MDS, MEC e pelo MTE.

16. Sobre o tema, ver dados do Observatório Jovem vinculado à Universidade Federal Fluminense. Disponível em: <http://www.observatoriojovem.org/>. 
sobre o Projovem Trabalhador, queremos registrar que se considerarmos que a região Sudeste tem uma população de jovens entre 15 e 24 anos estimada em 11 milhões (Baeninger, 1999) e que as qualificações do referido programa, somadas no período de 2008 a 2010, totalizam 379.739, segundo dados do próprio em 2010, em termos nacionais veremos que as qualificações no PNQ especificamente para essa faixa etária precisam crescer, da mesma forma que aquelas organizadas pelo Projovem Trabalhador.

Outro dado para nossa análise diz respeito à escolaridade. O PNQ (2003-07), em sua normatização, afirma que deve estar voltado para as populações mais vulneráveis economicamente e com as menores escolaridades. No entanto, a escolaridade de seus usuários está localizada na faixa do Ensino Médio completo, quando os brasileiros são detentores de média de 7,4 anos de estudo. Ainda que não possamos fazer uma avaliação linear de que a conclusão do Ensino Médio está relacionada, necessariamente, a uma maior renda, visto que existem outras variáveis que merecem ser consideradas neste sentido, entendemos que a média escolar do usuário do PNQ destoa do perfil do trabalhador brasileiro, revelando que o Plano não cumpre seu objetivo de chegar às populações mais frágeis em termos de acesso à educação. Contribuem para esse quadro o fato de que algumas formações (em especial no estado do Rio de Janeiro), exigem o Ensino Médio completo como requisito de acesso - o que entra em choque com a proposta do PNQ - e o caráter urbano do Plano. Entendemos que com o ingresso de trabalhadores usuários do Bolsa Família nos cursos do PNQ, por intermédio do PlanSeq/BF, a partir de 2008 e, mais intensamente, a partir de 2009, trará mudanças para o perfil educacional do PNQ, mas ainda não temos elementos para subsidiar essa informação.

Sobre o perfil empregatício dos usuários, vale ressaltar a predominância de trabalhadores autodenominados de "por conta própria" e desempregados. Sobre o assunto é preciso ressaltar que a maior fonte de divulgação do PNQ é o Sistema Nacional de Emprego (Sine), para onde são encaminhados trabalhadores recém-desempregados ou em busca de acesso ao emprego formal, e não há como negar que esse quadro influencia o perfil empregatício dos usuários. Segundo os dados analisados, porém, não nos foi possível verificar qual o nível de proteção social existente na categoria "por conta própria". Seriam trabalhadores autônomos que contribuem com o sistema previdenciário, ou seriam subempregados que vivem na total informalidade? Não conseguimos responder a essa indagação, mas levando em consideração os níveis de traba- 
lhadores desprotegidos no Brasil contemporâneo (50,7\% somente da mão de obra é protegida, conforme o IBGE em 2010), acreditamos que este grupo seja predominante.

A respeito das características dos cursos, destacamos seu aligeiramento (média de duração oficial é de duzentas horas, ${ }^{17}$ mas encontramos registros de formações realizadas com cargas menores), sua marginalidade quanto à formação escolar, visto que todos os cursos funcionam em estrutura à parte da aprendizagem formal e a simplicidade de seus conteúdos. Neste sentido, registramos que além dos aprendizados relativos ao fazer profissional em si, encontramos outros, relacionados ao cooperativismo, à economia solidária e ao empreendedorismo, os dois primeiros temas de grande relevância nas ações do governo atual.

As entidades executoras que mais se destacam quantitativamente na efetivação do Plano são o Sistema "S" e as ONGs (no momento, em franca expansão na execução desta ação), ou seja, apesar de se constituir em um sistema público de aprendizagem, dotado de financiamento de mesmo tipo, o PNQ é implementado pela iniciativa privada, tal qual a educação profissional brasileira, conforme dados do PNAD de 2007. O PNQ afirma-se, assim, como uma das estratégias de transferência do fundo público para execução de políticas também públicas, viabilizadas pelos setores privados.

Quanto aos recursos destinados ao Plano, verificamos que a qualificação de trabalhadores é a penúltima ação em investimento no Sistema Público de Emprego, demonstrando a pouca importância efetiva dada a essa política. Além disso, os custos dos cursos vêm crescendo, mas os recursos destinados sofrem significativa retração, o que com certeza tem implicações na já comentada qualidade dos mesmos. Concretamente, o governo Lula da Silva ainda não destinou $1 \%$ dos recursos do SPE à qualificação de trabalhadores, apesar de toda a propaganda oficial a respeito.

Resumindo o quadro aqui brevemente traçado, afirmamos que o PNQ tem chegado aos trabalhadores dos grandes centros urbanos, dotados de escolaridade média, atuantes nas áreas produtivas mais simples e desprotegidas, desempregados ou informais, que acessam as qualificações por meio do Sine, na

17. Duzentas horas/aula é o mínimo de aprendizagem estabelecida pelo Ministério do Trabalho. Verificamos que nos últimos anos este quantitativo de horas tem subido, alcançando esta média inicial, mas ainda são comuns os cursos com duração menor do que a preconizada, em especial fora das grandes cidades. 
busca por uma (re)inserção no mercado de trabalho formal. Em outras palavras, o PNQ, tal qual está estruturado, deixa de fora os trabalhadores com perfis mais precarizados, de baixa escolaridade, que jamais tiveram um emprego formal, ou que o fizeram há muito tempo e deixaram de buscá-lo.

Tratando agora da inserção produtiva dos Cras, podemos afirmar que nessa experiência encontramos uma formação ainda mais periférica e marginal do que o já precário aprendizado do PNQ. Neste sentido, afirmamos que essa experiência viabiliza um aprofundamento da dualidade estrutural em termos de formação, organizando uma aprendizagem relativa ao trabalho ainda mais precarizada.

Para melhor conhecermos essa ação, vejamos a configuração contemporânea da assistência e a efetivação dos Cras. A Política Nacional de Assistência Social (PNAS) aprovada em 2004 tem seus pilares contidos na Loas (Lei Orgânica da Assistência Social n. 8.742/1993), traduzidos no Suas (Sistema Único da Assistência Social). Os Cras devem ser uma das corporificações desse processo. Tais centros são as unidades principais de execução da política nacional de proteção social básica, sendo detentores de base territorial segundo níveis de vulnerabilidade social da região. Executa serviços socioassistenciais, focados nos mais frágeis em termos sociais e econômicos, ou seja, na população que sofre com os reflexos mais graves da desigualdade: desemprego, emprego precário, falta de moradia, ou moradia precária, desinformação, adoecimento, violência, falta de acesso a outras políticas públicas, entre outros.

Também chamados pelo Ministério do Desenvolvimento Social e Combate à Fome (MDS) de Casa da Família, os Cras têm a pobreza absoluta ${ }^{18}$ como foco da execução de suas políticas. Nesses espaços, segundo o MDS, devem ser prestados serviços como acolhimento, acompanhamento em serviços socio-

18. A pobreza absoluta pode ser definida por critério de renda (indivíduos que vivem com menos de um dólar ao dia é um dos parâmetros utilizados pelo Banco Mundial, por exemplo), acrescida de aspectos que se somam a esta e são multidimensionais, tais como dificuldades de acesso aos serviços públicos, à moradia, ao transporte. As políticas de assistência social têm hoje melhores níveis de efetividade junto às populações mais pobres, mas ainda existem grupos empobrecidos que não conseguem chegar até elas. Dentre estes, além dos que estão cadastrados e aguardam efetivo acesso ao PBF, temos aqueles grupos que não reúnem condições de acessar esse benefício. De um lado, as populações mais fragilizadas economicamente, que residem de modo itinerante, sem registro civil e longe das áreas urbanas, que sequer conseguem chegar aos Cras. De outro, os trabalhadores pobres que possuem renda per capita familiar superior aos R $\$ 137$ praticados pelo PBF. Estes grupos estão fora da política de assistência social. 
educativos e de convivência, ações socioassistenciais, encaminhamentos para a rede de proteção social e para os demais serviços das outras políticas sociais, orientação e apoio na garantia dos seus direitos de cidadania e de convivência familiar e comunitária, acesso a programas de transferência de renda. Concretamente, os atendimentos centrais dizem respeito à abordagem da pobreza, privação econômica, fragilização de vínculos familiares. Trata-se da tentativa de organizar uma nova operacionalização para uma política que tem como marcas históricas o assistencialismo, o atendimento precário realizado por instituições filantrópicas de perfil privado, marcada ainda pelo personalismo, emergencialismo e amadorismo, uma vez que é voltado para as populações que atuam nas franjas precaríssimas da produção e que desconhecem direitos básicos. Devido a essas determinações, os limites a ser transpostos não são poucos.

Da mesma forma que o PNQ, a inserção produtiva desenvolve-se junto ao público feminino, dessa vez mulheres chefes de família, usuárias da política de assistência social, em especial do Programa Bolsa Família (PBF). Nos Cras, são oferecidas aprendizagem de tarefas simples, recortadas por conteúdos relativos à autoestima e ao cooperativismo, com vistas à geração de renda, como estratégia de construção de uma suposta autonomia para futuro desligamento dessa política. Neste sentido, vale lembrar que em uma de suas falas, o então ministro do Desenvolvimento Social, Patrus Ananias, afirmou que a política de assistência social deve ter "portas de saída" para evitar que os usuários entrem e permaneçam na condição de "assistidos" por muito tempo. ${ }^{19}$ Esse tipo de percepção revela uma noção equivocada dos direitos sociais e do seu público demandatário. Preconceitos relativos à pobreza — os pobres são acomodados e não gostam de trabalhar - são revelados nesse tipo de afirmação. No entanto, as mulheres vinculadas à assistência social, conforme revela o próprio MDS, são trabalhadoras e possuem renda proveniente do trabalho doméstico ou do comércio informal, buscando a inserção produtiva como complemento de renda e espaço de convivência.

As entidades promotoras dessa aprendizagem são instituições assistenciais municipais, em geral ONGs, que já realizam ação semelhante em seus muros e

19. Trata-se da velha máxima liberal de que o apoio ao trabalhador, por intermédio do fundo público, acomoda-o nessa condição e deve durar pouco tempo, estando aquém das menores remunerações normatizadas. Críticas relativas à acomodação do capital frente à transferência de recursos públicos para sua sobrevivência não são feitas. 
estabelecem parcerias com os Cras. Os professores são também chamados de oficineiros e atuam sob prisma informal. A média escolar dos usuários está situada nas séries finais do Ensino Fundamental, e as aprendizagens mais comuns são as do campo do artesanato e estética (manicure e práticas simples de cabeleireiro). ${ }^{20}$ Como resultado final das oficinas, são realizados bazares e feiras com o propósito de comercializar os objetos confeccionados, o que possui limites evidentes e não possibilita a geração de renda e de autonomia almejadas.

O Ministério o Desenvolvimento Social e o Programa das Nações Unidas para o Desenvolvimento (PNUD) têm estimulado a organização de parcerias com instituições formais de educação para a realização das aprendizagens nos Cras. No entanto, diante da ausência de destinação de recursos específicos para esse fim, raras foram as experiências estruturadas com algum tipo de suporte de instituições de ensino formal. Sendo assim, em meio à precariedade e à ausência de recursos, o que se produz é uma aprendizagem empobrecida para os pobres, na expectativa de gerar acesso ao mercado de trabalho e à renda. Destituída de infraestrutura material e humana, desarticulada de outras políticas de cunho educacional e do trabalho, completamente alijada do ensino formal, dotada de caráter imediatista, a inserção produtiva fica caracterizada por sua precariedade e pelo tom caricatural com que constrói a aprendizagem de trabalhadores. Portanto, trata-se de uma experiência ainda mais frágil, simplificada e empobrecida do que aquela oferecida no PNQ.

\section{A reposição da aprendizagem simples e empobrecida para os trabalhadores pobres}

Partimos do princípio de que o PNQ, como integrante do Plano Plurianual, faz parte de um projeto de desenvolvimento que inclui a preparação de força de trabalho para as ocupações mais simples, permitindo melhor acesso à renda e ao consumo, como um de seus eixos, da mesma forma que a inserção produtiva dos Cras. Estamos falando da organização de um projeto de formação de mão de obra para áreas periféricas, desvinculado dos demais projetos de apren-

20. Quando os CRAS possuem infraestrutura física melhor, com espaço físico adequado e mais recursos financeiros, costumam ser oferecidos cursos na área da culinária básica. 
dizagem profissional (do ensino profissionalizante de nível médio e superior, por exemplo), bem como da produção de ciência e tecnologia e da valorização da cultura, distanciado ainda da própria escola formal, o que evidencia as limitações das propostas em curso.

Um país continental, com campos produtivos diversos e significativo número de jovens (para falarmos apenas de parte do público a que se destinam as qualificações), demanda verdadeiramente um projeto de formação que comporte, inclusive, aprendizagens dos níveis fundamentais. O modelo para tanto, porém, não pode estar limitado a aprendizagens simples e aligeiradas, frágeis na execução e na viabilização da permanência nos cursos, tal como tem ocorrido no PNQ e na proposta de inserção produtiva dos Cras. Com perfil atual, o que se efetiva e aprofunda é a perpetuação de um modelo produtivo organizado sobre a produção de bens simples e sobre o isolamento da produção científica em algumas poucas ilhas de excelência, gerando um plano de formação não abrangente, fragilíssimo de conteúdos, empobrecido no fazer profissional e no pensar a profissão, que aceita e aprofunda a condição de periferia produtiva do país na divisão internacional do trabalho.

As expectativas da sociedade brasileira frente à eleição de um governo com trajetória de esquerda não tem se confirmado, e a dicotomia entre o que é afirmado e o que é efetivamente realizado, é gritante, em especial no campo ora analisado. Observando ambas as experiências, verificamos estar diante de uma formação periférica no Plano, que corporifica a dualidade estrutural presente na educação brasileira e que estabelece no interior dessa uma nova dualidade, a da inserção produtiva dos Cras. Em outras palavras, a inserção produtiva dos Cras oferece aprendizado ainda mais precário do que o praticado no PNQ, revelando um aprendizado periférico, nas margens de outro aprendizado periférico.

Finalizando a presente reflexão, registramos que a qualificação de trabalhadores se adequa ao projeto de desenvolvimento nacional em curso - aqui entendido como neoliberal, dotado de discurso social, ou desenvolvimentista, subordinado e empobrecido. Por intermédio do PNQ e da inserção produtiva dos Cras, têm sido preparada força de trabalho periférica, que realizará atividades simples e desprotegidas no mercado informal. Esses trabalhadores informais representam quase a metade da PEA, segundo já sinalizado aqui, e não podem ser desconsiderados por um projeto de desenvolvimento que se pretenda agregador e conciliador de demandas do capital e trabalho (e o atual governo atua 
nesse sentido). Essa força de trabalho representa um subproletariado (Antunes, 1995) que não pode ter sua existência negada e que precisa se integrar aos processos produtivos, de circulação e de consumo, ainda que perifericamente. Neste sentido, é inegável que esses programas buscam valorizar a condição de consumidor e portador de conta bancária daquelas populações que estavam às margens desses processos. Trata-se, portanto, de conferir às mesmas uma cidadania limitada ao consumo e ao CPF.

Esta abordagem é útil ao projeto de desenvolvimento em processo. É preciso torná-los mais produtivos e consumidores ativos, é preciso neutralizar resistências a essa ordem, educar e adaptar os mais pobres para estes tempos de trabalho precário e frágil. Vale ressaltar que em ambas as experiências, tanto no PNQ quanto nos Cras, a capacidade de inserção ao mercado de trabalho formal é mínima - no caso do PNQ, o estudo do acesso dos usuários ao mercado de trabalho é pouco aprofundado nos instrumentos de avaliação do Plano. Já no caso dos Cras, a meta é a geração de renda, o que fica bastante limitado, considerando os objetos produzidos (produtos artesanais) e sua capacidade de comercialização. Isto posto, entendemos que a potencialidade de ambas as experiências é muito mais ideológica do que concreta. Este quadro evidencia os limites dessas experiências, revelando o quanto estas ações sofisticam a aprendizagem simples realmente existente.

Recebido em nov./2010 n Aprovado em mar./2011

\section{Referências bibliográficas}

ALVES, Giovani. O novo (e precário) mundo do trabalho: reestruturação produtiva e crise do capitalismo. São Paulo: Boitempo, 2000.

ANTUNES, Ricardo. Adeus ao trabalho? Ensaio sobre as metamorfoses e a centralidade do mundo do trabalho. 3. ed. São Paulo: Cortez, 1995.

BAENINGER, Rosana. Demografia da população jovem Cadernos da Juventude, Saúde e Desenvolvimento, Brasília, v. 1, ago. 1999.

BARATA, Josefa Batista. Os desafios, 30 anos depois. Revista Inscrita, Brasília, CFESS, ano VIII, n. XII, nov. 2009. 
BEHRING, Elaine Rossetti. Politica social no capitalismo tardio. São Paulo: Cortez, 1998.

BORGES, Altamiro; POCHMANN, Marcio. Era FHC: a regressão do trabalho. São Paulo: Anita Garibaldi, 2002.

BORÓN, Atilio A. El estado y las "reformas del Estado orientadas al mercado". Los “desempeños" de la democracia en América Latina. In: KRAWCZYK, Nora Rut; WANDERLEY, Luiz Eduardo (Orgs.). América Latina: Estado e reformas numa perspectiva comparada. São Paulo: Cortez, 2003. p.153-184.

BRASIL. Lei n. 8.352, de 28/12/1991, que dispõe sobre as disponibilidades financeiras do FAT.

Ministério do Trabalho e Emprego (MTE). Sistema público de emprego e educação profissional: implementação de uma política integrada. Brasília, 1996.

. Planfor. Plano Nacional de Formação Profissional. MTE. Termo de referência de Projetos Especiais, 1996a.

. Dieese, Cesit. Emprego e desenvolvimento tecnológico. Artigos dos pesquisadores nos seminários internacional e regionais "Emprego e Desenvolvimento Tecnológico”. São Paulo, 1999.

. Ministério do Trabalho e Emprego (MTE). Secretaria de Políticas Públicas de Emprego, Departamento de Qualificação. PNQs/Plantesqs. Indicadores de Desempenho Planfor/PNQ 2003/2004. Brasília: MTE, SPPE.

. Plano Nacional de Qualificação (PNQ) 2003/2007. MTE. Disponível em: <www.sine.pr.gov.br/setp/cqp/Pnq_2003_07.pdf>. Acesso em: 2 jul. 2006.

. Dieese. Departamento Intersindical de Estatística e Estudos Socioeconômicos. Anuário da Qualificação Social e Profissional, 2006. Disponível em: <http://www. dieese.org.br/anu/Anuario_qualificacao_profissional.pdf>.Acesso em: 2 jan. 2009.

. Dieese. Departamento Intersindical de Estatística e Estudos Socioeconômicos. Anuário da Qualificação Social e Profissional, 2007. Disponível em: <www.mte.gov.br>. Acesso em: 2 jan. 2009.

. Dieese. Departamento Intersindical de Estatística e Estudos Socioeconômicos. Anuário dos Trabalhadores, 2005. Disponível em: <http://www.mte.gov.br/pnq/anuario_2005.pdf>.Acesso em: 12 mar. 2008.

. Dieese. Departamento Intersindical de Estatística e Estudos Socioeconômicos. Anuário da Qualificação Social e Profissional, 2008. Disponível em: <www.mte.gov.br>. Acesso em: 2 jan. 2009. 
BRASIL. Disponível em: <http://www.mds.gov.br/sites/conferencias-1/publicacoes-1/ publicacoes $/$ ?searchterm $=$ Financiamento $\% 20 \mathrm{da} \% 20$ assist $\% \mathrm{C} 3 \%$ AAncia $\% 20$ social $>$. Acesso em: 1 set. 2008.

. IBGE/PNAD. Pesquisa Nacional por Amostra de Domicílios - Volume Brasil, 2007. Disponível em: <www.ibge.gov.br/home/estatistica/populacao/trabalhoerendimento/pnad2007/default.shtm>. Acesso em: 1 set. 2008.

. IBGE. Instituto Brasileiro de Geografia e Estatística. Pesquisa Economia Informal Urbana. Disponível em: <www.ibge.gov.br>. Acesso em: 4 jan. 2008.

. Loas. Lei n. 8.742/93. Lei Orgânica da Assistência Social. Disponível em: $\overline{<h t t p: / / w w w . r i o . r j . g o v . b r / s m a s / l o a s . p d f>. ~ A c e s s o ~ e m: ~} 12$ mar. 2008.

. Ministério do Desenvolvimento Social e Combate à Fome (MDS). Promoção da Inclusão Produtiva (MDS, 2007). Disponível em: <http://www.mds.gov.br/sites/ qualificacao de instituicoes-para-participacao-em-processo-seletivo-para-implementacao -de-projetos-de-inclusao-produtiva/inclusao-produtiva/?searchterm=inclus $\% \mathrm{C} 3 \%$ A3o\%20produtiva $>$. Acesso em: 1 jul. 2008.

. Lei n. 11.692/2008. Dispõe sobre o Programa Nacional de Inclusão de Jovens (Projovem). Disponível em: <http://www.planalto.gov.br/ccivil_03/_Ato2007-2010/2008/ Lei/L11692.htm>. Acesso em: 24 fev. 2009.

. Dieese. Caged - Cadastro Geral de Empregados e Desempregados, mar. 2009. Disponível em: <http://www.cntm.org.br/materias/imagens/\%7B25E3DE03-9AF0-49 A4-8DB7-B2BB9D2EE3A8\%7D_empregomar\%C3\%A7o.pdf.pdf $>$. Acesso em: 7 maio 2009.

. IBGE, Instituto Brasileiro de Geografia e Estatística e Associação Brasileira de ONGs (Abong). As fundações privadas e associações sem fins lucrativos no Brasil, 2005. Disponível em: $<$ http://www.ibge.gov.br/home/estatistica/economia/fasfil/2005/>. Acesso em: 12 mar. 2009.

. IBGE. Pesquisa Mensal de Emprego, fev. 2009. Disponível em: <http://www. ibge.gov.br/home/estatistica/indicadores/trabalhoerendimento/pme_nova/pme-rj_ 200902 comentarios.pdf>. Acesso em: 3 abr. 2009.

. IBGE/PNAD 2007. Perfil da educação de jovens e adultos e da educação profissional no Brasil. Disponível em: <http://www.ibge.gov.br/home/presidencia/ noticias/noticia_visualiza.php?id_noticia=1375\&id_pagina=1>. Acesso em: 22 maio 2009.

. Lei n. 8.352, de 28 de dezembro de 1991. Dispõe sobre as disponibilidades financeiras do Fundo de Amparo ao Trabalhador (FAT) e dá outras providências. [Con- 
versão da MPV n. 301, de 1991]. Publicado no DOU, de 31/12/1991. Disponível em: <http://www.planalto.gov.br/CCIVIL/Leis/L8352.htm>. Acesso em: 1 set. 2008.

Ipea. Mapa do Emprego. In: CAMPOS, André; AMORIM, Ricardo. Demanda e perfil dos trabalhadores formais no Brasil em 2007. Disponível em: <http://www. ipea.gov.br/sites/000/2/destaque/mapadoemprego.pdf>. Acesso em: 2 maio 2009.

. Ministério da Fazenda. PAC. Programa de Aceleração do Crescimento. Disponível em: <http://www.fazenda.gov.br/portugues/releases/2007/r220107-PAC.pdf>. Acesso em: 12 fev. 2009.

. Ministério do Desenvolvimento Social e Combate à Fome. Jornal MDS, Assessoria de Comunicação Social, Brasília, n. 12-3, fev. 2009.

. Ministério do Desenvolvimento Social e Combate à Fome (MDS). Cras, institucional. Disponível em: <http://www.mds.gov.br/servicos/fale-conosco/assistencia-social/gestor-tecnico-municipal/psb-2013-protecao-social-basica/cras-2013-instituciona $1 /$ ? searchterm $=$ Programas $\% 20$ desenvolvidos $\% 20$ nos $\% 20$ CRAS $>$. Acesso em: 1 jul. 2009.

. Ministério do Desenvolvimento Social e Combate à Fome (MDS). MDS em números/Sudeste/Rio de Janeiro. Disponível em: <http://www.mds.gov.br/sites/ mds-em-numeros/paginas/regioes/sites/mds-em-numeros/paginas/estados/rio_de_janeiro>. Acesso em: 23 abr. 2009.

. Ministério do Trabalho e Emprego (MTE). Indicadores de mobilidade ocupacional. Dados do Sistema. Sine, 2008. Disponível em: <http://www.mte.gov.br/sine/ relatorio_anual2008.pdf>. Acesso em: 12 abr. 2009.

. Ipea/Secretaria Especial de Políticas para as Mulheres e Unifem. Retratos da desigualdade de gênero e raça. 3. ed. Brasília, 2008. Disponível em: <http://www.ipea. gov.br/sites/000/2/destaque/Pesquisa_Retrato_das_Desigualdades.pdf $>$. Acesso em: 4 abr. 2009.

BRAZ, Marcelo. O PAC e o serviço social: crescimento para quê e para quem? Os setenta anos da profissão e seus desafios conjunturais. Serviço Social \& Sociedade, ano XXVIII, São Paulo, n. 91, 2007.

CAMPOS, André; AMORIM, Ricardo. Demanda e perfil dos trabalhadores formais no Brasil em 2007. Rio de Janeiro: Ipea, 2007. Disponível em: <http:/www.ipea.gov. br/sites/000/2/destaque/mapadoemprego.pdf>. Acesso em: 2 maio 2009.

CAMPOS, Maria Malta. Educação e políticas de combate à pobreza. Revista Brasileira de Educação, n. 243, set./out./nov./dez. 2003. 
CEA, Georgia Sobreira dos Santos. A qualificação profissional como instrumento de regulação social. $27^{\mathrm{a}}$ Reunião da Anped, 2004. Disponível em: <http://www.anped.org. br/reunioes/27/gt09/t099.pdf>. Acesso em: 7 mar. 2009.

. Planfor, reforma do Estado e acumulação flexível: tecendo fios invisíveis. Educere et Educare. Revista de Educação, v. I, n. 2, p. 229/244, jul./dez. 2006. Disponível em: <e-revista.unioeste.br/index.php/educererevistaeducacao/article/vewfile/206/195>. Acesso em: 12 maio 2008.

CONFEDERAÇÃO NACIONAL DA INDÚSTRIA (CNI). Educação para a nova indústria. Uma ação para o desenvolvimento sustentável. Proposta de ação do Sistema Indústria, em consonância com as diretrizes do mapa estratégico da indústria. CNI, Sesi, Senai, ago. 2007. Disponível em: <http://www.cni.org.br/portal/data/pages/8A9015D 218CCF2730118CD1BA3180A08.htm>. Acesso em: 21 jan. 2009.

COUTINHO, Carlos Nelson. O Estado brasileiro: gênese, crise, alternativas. In: LIMA, Júlio César França; NEVES, Lucia Maria Wanderley. Fundamentos da educação escolar no Brasil contemporâneo. Rio de Janeiro: Editora Fiocruz, 2006.

CUNHA, Luís Antonio. Educação, Estado e democracia no Brasil. 2. ed. São Paulo: Cortez; Niterói, Editora Universidade Federal Fluminense, 1995.

. O ensino de ofícios nos primórdios da industrialização. São Paulo: Unesp, 2000a. $2000 \mathrm{~b}$.

. O ensino profissional na irradiação do industrialismo. São Paulo: Unesp,

DEDECCA, Claudio Salvadori; BARBOSA, Alexandre Freitas; MORETTO, Amilton. Transformações recentes de empregos nos países desenvolvidos: tendências e particularidades. In: OLIVEIRA, Roberto Veras de. Novo momento para as comissões de emprego no Brasil? Sobre as condições da participação e controles sociais no sistema público de emprego em construção. São Paulo: A+Comunicação e Unitrabalho, 2007.

DEPARTAMENTO INTERSINDICAL DE ESTATÍSTICA E ESTUDOS SÓCIO-ECONÔMICOS (Dieese). Anuário da Qualificação Social e Profissional: 2006. São Paulo: Dieese, 2007. Disponível em: <http://www.dieese.org.br/anu/Anuario_qualificacao_profissional.pdf>. Acesso em: dez. 2008.

. Anuário da Qualificação Social e Profissional: 2007. São Paulo: DIEESE, 2007a.280p. Disponível em: <http://www.mte.gov.br/dados_estatisticos/Anuario_qualificacao_profissional_2007.pdf>.Acesso em: dez. 2008. 
DEPARTAMENTO INTERSINDICAL DE ESTATÍSTICA E ESTUDOS SÓCIO-ECONÔMICOS (Dieese). Anuário dos Trabalhadores: 2008. São Paulo: Dieese, 2008. 264p. Disponível em: <http://www.mtb.gov.br/dados_estatisticos/anuario_2008/arquivos/pdf/ anuario_trabalhadores_2008.pdf>. Acesso em: dez. 2008.

FIDALGO, Fernando; FIDALGO, Nara Luciene Rocha. Refluxos sociais da lógica das competências: o processo de individualização em foco. In: ; OLIVEIRA, Maria Auxiliadora Monteiro (Orgs.). Educação profissional e a lógica das competências. Petrópolis: Vozes, 2007.

FRIGOTTO, Gaudêncio. A produtividade da escola improdutiva. 4. ed. São Paulo: Cortez, 1993.

FRIGOTTO, Gaudêncio. Educação e crise do capitalismo real. São Paulo: Cortez, 1995.

FRIGOTTO, Gaudêncio. Educação e crise do trabalho assalariado e do desenvolvimento: teorias em conflito. In: (Org.). Educação e crise do trabalho: perspectivas de final de século. Petrópolis: Vozes, 1998.

GENTILI, Pablo A. A.; SILVA, Tomaz Tadeu da (Org.). Neoliberalismo, qualidade total e educação: visões críticas. 4. ed. Petrópolis: Vozes, 1994.

GONÇALVES, Reinaldo. Crise econômica: radiografia e soluções para o Brasil. Rio de Janeiro: Fundação Lauro Campos, 2008.

GONÇALVES, Reinaldo. Crise econômica: radiografia e soluções para o Brasil. Rio de Janeiro: Fundação Lauro Campos, 2008. Disponível em: < http://www.socialismo. org.br/portal/economia-e-infra-estrutura/101-artigo/604-crise-economica-radiografia-e-solucoes-para-o-brasil>. Acesso em: 2 jan. 2009.

GRAMSCI, Antônio. Os intelectuais e a organização da cultura. 6. ed. Rio de Janeiro: Civilização Brasileira, 1988.

GURGEL, Claudio. A gerência do pensamento: gestão contemporânea e consciência neoliberal. São Paulo: Cortez, 2003.

HARVEY, David. A condição pós-moderna. São Paulo: Loyola, 2003.

HOBSBAWM, Eric. O novo século: entrevista a Antonio Polito. São Paulo: Companhia das Letras, 2009.

IBASE. Repercussões do PBF na segurança alimentar e nutricional das famílias beneficiadas. Disponível em: <http://www.ibase.br/>. Acesso em: 12 jun. 2008. 
KRÜGER, Valdelucia Amaral. As determinações restritivas das políticas públicas de qualificação profissional e os limites do PNQ. UFPR. Disponível em: <www.ppgte. cefetpr.br/dissertacoes/2006/valdelucia/pdf>. Acesso em: 22 nov. 2007.

KUENZER, Acacia. A exclusão includente e a inclusão excludente: a nova forma de dualidade estrutural que objetiva as novas relações entre educação e trabalho. Semana pedagógica Paraná. Disponível em: <http://www.diaadia.pr.gov.br/det/arquivos/File/ SEMANAPEDAGOGICA/13_Exclusao-Includente-Acacia_Kuenzer.pdf $>$. Acesso em: 8 maio 2009.

. A educação profissional nos anos 2000. A dimensão subordinada das políticas de inclusão. Educação \& Sociedade, Campinas, v. 27, n. 96, out. 2006. Disponível em: $<$ http://www.scielo.br/pdf/es/v27n96/a12v2796.pdf>. Acesso em: 12 mar. 2009.

MANACORDA, Mario Alighiero. História da educação: da antiguidade aos nossos dias. 8. ed. São Paulo: Cortez, 2000.

MANFREDI, Silvia Maria. Educação profissional no Brasil. São Paulo: Cortez, 2003.

MARTINS, Heloisa Hlena. O processo de reestruturação produtiva e o jovem trabalhador: conhecimento e participação. Tempo Social. Revista de Sociologia da USP, São Paulo, nov. 2001.

MARX, Karl. O capital. Crítica da economia política. O processo de produção de capital. São Paulo: Nova Cultural, 1985.

MEC. Inep. Censo Escolar 2005. Disponível em: <www.inep.gov.br/basica/censo>. Acesso em: 22 mar. 2008.

MÉSZÁROS, István. Desemprego e precarização: um grande desafio para a esquerda. In: ANTUNES, Ricardo (Org.). Riqueza e miséria do trabalho no Brasil. São Paulo: Boitempo Editorial, 2006.

NETTO, José Paulo. Marxismo impenitente: contribuição à história das idéias marxistas. São Paulo: Cortez, 2004.

NEVES, Lúcia Maria Wanderley; SANT’ANNA, Ronaldo. Introdução: Gramsci, o Estado educador e a nova pedagogia da hegemonia. In: NEVES, Lúcia Maria Wanderley. A nova pedagogia da hegemonia: estratégias do capital para educar o consenso. São Paulo: Xamã, 2005.

OBSERVATÓRIO JOVEM. IBGE divulga perfil da EJA e da educação profissional no país. Disponível em: $<$ http://www.observatoriojovem.org/materia/ibge-divulga-perfil -da-eja-e-da-educa $\% \mathrm{C} 3 \% \mathrm{~A} 7 \% \mathrm{C} 3 \% \mathrm{~A} 30-$ profissional-no-pa $\% \mathrm{C} 3 \% \mathrm{ADs}>$. Acesso em: 1 jun. 2009. 
OLIVEIRA, Ramon. Agências multilaterais e a educação profissional brasileira. Campinas: Alínea, 2006

PNUD. Programa das Nações Unidas para o Desenvolvimento. Programa de objetivos do milênio. Disponível em: <http://www.ipea.gov.br/sites/000/2/download/TerceiroRelatorioNacionalODM.pdf>. Acesso em: 2 abr. 2009.

POCHMANN, Marcio. Inserção ocupacional e o emprego dos jovens. São Paulo: Abet, 1998

PROJOVEM URBANO EM REVISTA. Balanço. Disponível em: <http://www.projovemurbano.gov.br/pjurevista/balanco.html>. Acesso em: 27 ago. 2010.

RAMOS, Marise Nogueira. Pedagogia das competências: autonomia ou adaptação? São Paulo: Cortez: 2001.

RODRIGUES, José. O moderno príncipe industrial: o pensamento pedagógico da Confederação Nacional da Indústria. Campinas: Autores Associados, 1998.

RUMMET, Sonia Maria. Educação e identidade de trabalhadores: as concepções do capital e do trabalho. Niterói: Xamã, 2000.

SAUL, Ana Maria; FREITAS, José Cleber. Políticas públicas de qualificação: desafios atuais. São Paulo: A+Unitrabalho, 2006.

; José Cleber de; PONTUAL, Pedro de Carvalho; KOYAMA, Sérgio Mikio. A avaliação do Plano Nacional de Qualificação. Construindo referenciais. In: Novo momento para as comissões de emprego no Brasil? Sobre as condições da participação e controle sociais no sistema público de emprego em construção. São Paulo: A+Unitrabalho: A+ Comunicação, 2007. 2 v.

; FREITAS, José Cleber de; KOYAMA, Sérgio Mikio; LUNA, Sergio Vasconcelos de. Pesquisa com egressos das ações dos Plan TeQs. In: (Orgs.). Políticas públicas de qualificação. São Paulo: A+Unitrabalho, 2007a.

; KOYAMA, Sérgio Mikio; LUNA, Sergio Vasconcelos de. Síntese avaliativa dos Planos Territoriais de Qualificação (PlanTeQs) 2003-2005. In: (Orgs.). Políticas públicas de qualificação. São Paulo: A+Unitrabalho, 2007b.

SAVIANI, Demerval. O trabalho como princípio educativo frente às novas tecnologias. In: FERRETTI, Celso João; ZIBAS, Dagmar; MADEIRA, Felícia; FRANCO, Maria Laura (Org.). Novas tecnologias de trabalho e educação: um debate multidisciplinar. Petrópolis: Vozes, 1994.

SENNETT, Richard. A corrosão do caráter: conseqüências pessoais do trabalho no novo capitalismo. São Paulo: Record, 2004. 
SETRAB/RJ. Guia PlanTeQ/2008. Secretaria de Estado de Trabalho e Renda. Disponível em: $<$ http://www.trabalho.rj.gov.br/download/PlanTeQ2008.pdf $>$. Acesso em: 12 dez. 2008.

SOARES, Laura Tavares Ribeiro. Os custos sociais do ajuste neoliberal na América Latina. São Paulo: Cortez, 2002. (Col. Questões da Nossa Época.)

TOFFLER, A. A terceira onda. Rio de Janeiro: Record, 1980. 